\title{
Efficient Production of Nisin A from Low-Value Dairy Side Streams Using \\ a Nonengineered Dairy Lactococcus lactis Strain with Low Lactate Dehydrogenase Activity
}

Ge Zhao ${ }^{\mathrm{a}}$, Jianming Liu ${ }^{\mathrm{a}}$, Jie Zhao ${ }^{\mathrm{b}}$, Robin Dorau ${ }^{\mathrm{a}}$, Peter Ruhdal Jensen ${ }^{{ }^{*}}$,Christian Solem ${ }^{\mathrm{a}^{*}}$

${ }^{a}$ National Food Institute, Technical University of Denmark, DK-2800 Kgs. Lyngby, Denmark

${ }^{\mathrm{b} K e y ~ L a b o r a t o r y ~ o f ~ D a i r y ~ B i o t e c h n o l o g y ~ a n d ~ E n g i n e e r i n g, ~ M i n i s t r y ~ o f ~ E d u c a t i o n, ~ I n n e r ~}$

Mongolia Agricultural University, Hohhot 010018, China 
Table S1 MICs for 9 antibiotics of donor strain ATCC11454 and recipient strain RD1M5 using broth dilution method.

\begin{tabular}{cccccccccc}
\hline \multirow{2}{*}{ Strain } & \multicolumn{1}{l}{${ }^{\mathrm{a}} \mathrm{MIC}(\mu \mathrm{g} / \mathrm{mL})$} & & & & & & \\
\cline { 2 - 10 } & Amp & Ery & Tet & Rif & Cl & Spe & Str & Kan & Neo \\
ATCC11454 & 1 & 0.04 & 0.32 & $>512$ & 4 & $>512$ & 64 & 8 & $>512$ \\
RD1M5 & 0.64 & 0.04 & 0.32 & 128 & 1 & 8 & 16 & 4 & 128 \\
\hline
\end{tabular}

${ }^{\mathrm{a}} \mathrm{MIC}$ assays were performed in duplicates. Antibiotic abbreviations: Amp, ampicillin; Ery, erythromycin; Tet, tetracycline; Rif, rifampin; Cl, chloramphenicol; Spe, spectinomycin; Str, streptomycin; Kan, kanamycin; Neo, neomycin. 


\section{Constituent}

Concentration in SA selective medium

(pH 7)

$\begin{array}{lc}\text { L-Alanine } & 3.4 \mathrm{mM} \\ \text { L-Arginine } & 1.1 \mathrm{mM} \\ \text { L-Asparagine } & 0.8 \mathrm{mM}\end{array}$

L-Cysteine

$0.8 \mathrm{mM}$

L-Glutamate

$2.1 \mathrm{mM}$

L-Glutamine

$0.7 \mathrm{mM}$

Glycine

$2.7 \mathrm{mM}$

L-Histidine

$0.3 \mathrm{mM}$

L-Isoleucine

$0.8 \mathrm{mM}$

L-Leucine

$0.8 \mathrm{mM}$

L-Lysine- $\mathrm{HCl}$

$1.4 \mathrm{mM}$

L-Methionine

$0.7 \mathrm{mM}$

L-Phenylalanine

$1.2 \mathrm{mM}$

L-Proline

$2.6 \mathrm{mM}$

L-Serine

$2.9 \mathrm{mM}$

L-Threonine

$1.7 \mathrm{mM}$

L-Tryptophan

$0.5 \mathrm{mM}$

L-Tyrosin

$0.3 \mathrm{mM}$

L-Valine

$0.9 \mathrm{mM}$

$\mathrm{NH}_{4} \mathrm{Cl}$

$9.5 \mathrm{mM}$

$\mathrm{K}_{2} \mathrm{SO}_{4}$

$0.28 \mathrm{mM}$

$\mathrm{KH}_{2} \mathrm{PO}_{4}$

$1.3 \mathrm{mM}$ 


\begin{tabular}{cc}
\hline Na-acetate & $15 \mathrm{mM}$ \\
MOPS & $40 \mathrm{mM}$ \\
Tricine & $4 \mathrm{mM}$ \\
$\mathrm{CaCl}_{2}$ & $0.0005 \mathrm{mM}$ \\
$\mathrm{MgCI}_{2}$ & $0.52 \mathrm{mM}$ \\
FeSO $_{4}$ & $0.001 \mathrm{mM}$ \\
NaCl & $50 \mathrm{mM}$ \\
Lactose & $0.5 \%$ \\
TTC & $0.01 \%$ \\
Agar & $1.5 \%$ \\
Nisin & $25 \mu \mathrm{g} / \mathrm{mL}$ \\
Vitamins & + \\
Micronutrients & + \\
Nucleosides & + \\
\hline
\end{tabular}

aVitamins: $0.4 \mu \mathrm{M}$ biotin, $10 \mu \mathrm{M}$ pyridoxal- $\mathrm{HCl}, 2.3 \mu \mathrm{M}$ folic acid, $2.6 \mu \mathrm{M}$ riboflavin, $8 \mu \mathrm{M}$ niacinamide, $3 \mu \mathrm{M}$ thiamine- $\mathrm{HCl}$, and $2 \mu \mathrm{M}$ pantothenate.

bMicronutrients: $0.003 \mu \mathrm{M}\left(\mathrm{NH}_{4}\right)_{6}\left(\mathrm{MO}_{7}\right)_{24}, 0.4 \mu \mathrm{M} \mathrm{H}_{3} \mathrm{BO}_{3}, 0.03 \mu \mathrm{M} \mathrm{CoCl}_{2}, 0.01 \mu \mathrm{M} \mathrm{CuSO}_{4}$, $0.08 \mu \mathrm{M} \mathrm{MnCl}_{2}$, and $0.01 \mu \mathrm{M} \mathrm{ZnSO}_{4}$.

'Nucleosides: $20 \mathrm{mg} /$ liter adenosine, $20 \mathrm{mg} /$ liter guanosine, $20 \mathrm{mg} /$ liter uridine, $20 \mathrm{mg} / \mathrm{liter}$ cytosine, $20 \mathrm{mg} /$ liter inosine, and $20 \mathrm{mg} / \mathrm{liter}$ thymidine. 

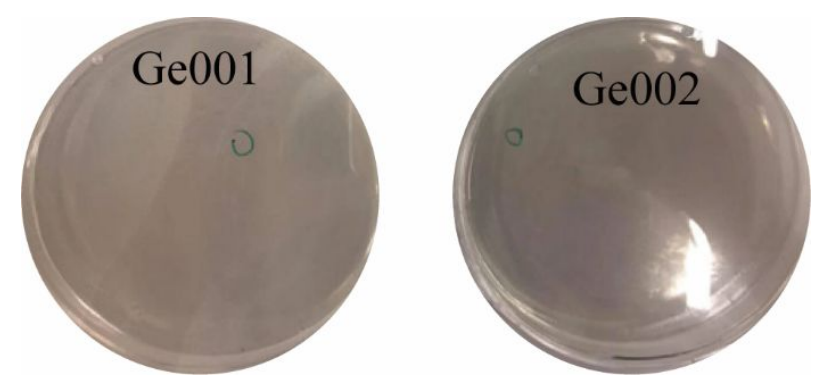

Figure S1. Presumptive transconjugants obtained on selective plates containing $25 \mu \mathrm{g} / \mathrm{mL}$ nisin. The red color signifies absence of lactate formation. 


\begin{tabular}{ccccccc}
\hline & $\mathrm{a}$ & $\mathrm{b}$ & $\mathrm{c}$ & $\mathrm{d}$ & $\mathrm{e}$ & $\mathrm{f}$ \\
\hline Strain & ATCC11454 & RD1M5 & Ge001 & Ge001 & Ge002 & Ge002 \\
Medium & SM17 & LM17 & SM17 & LM17 & SM17 & LM17 \\
OD 600 & 2.2 & 5.4 & 4.5 & 4.13 & 0.62 & 5.2 \\
pH & 4.77 & 6.01 & 6.19 & 6.32 & 6.87 & 6.44 \\
\hline
\end{tabular}

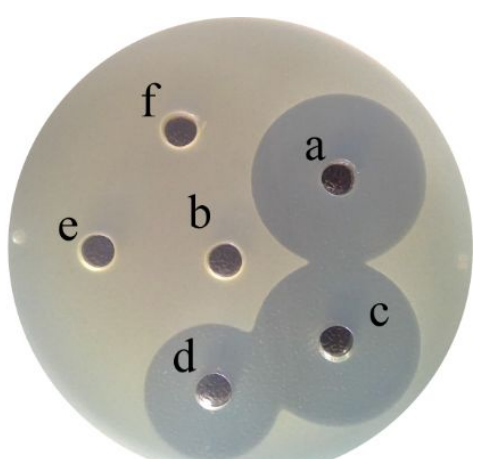

Figure S2. Preliminary confirmation of transconjugants based on sucrose-fermenting ability and inhibition assay. The strains were grown in M17 with $0.5 \%$ sucrose (SM17) or $0.5 \%$ lactose (LM17) at $30^{\circ} \mathrm{C}$ for $24 \mathrm{~h}$. Sample extracts were prepared and tested for ATCC11454, RD1M5 and the two transconjugants $\mathrm{Ge} 001$ and $\mathrm{Ge} 002$. In the right inhibition plate, a, b, c, d, e, and f indicates ATCC11454 (SM17), RD1M5 (LM17), Ge001 (SM17), Ge001(LM17), Ge002 (SM17), and Ge002 (LM17), respectively. 
A

Ge001 Left

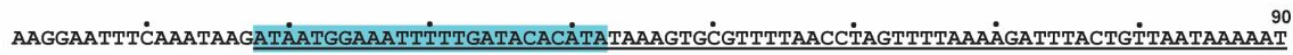

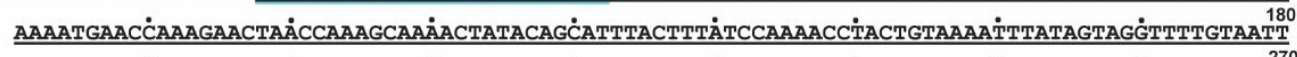

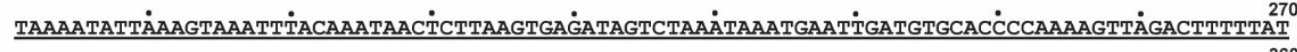

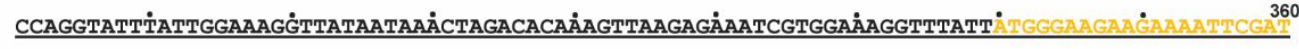

Ge001 Right

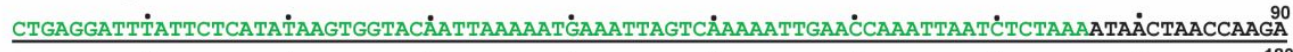

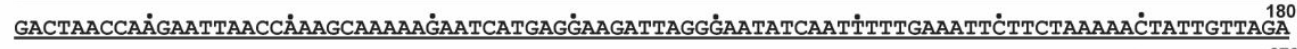

B GACTTTTGA $\dot{G} G A A G A A T A A \dot{G} G A A G T A T A A \dot{T} T A A A A A T A T \dot{A} A T G G A A A T T \dot{T} T T G A T A C A C \dot{A} T A \dot{A} C T C A T C T \dot{A} A A T A C T A G T \dot{G A A T T T T G A A G G}$

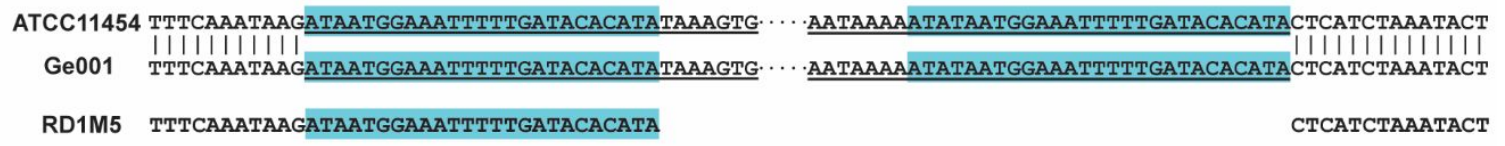

Figure S3. (A) The nucleotide sequences of the left and right termini of Tn5307 and the junction regions in Ge001. Tn5307-specific sequences are underlined and the direct repeated sequences are highlight in cyan. The first 21 nucleotides of the transposase, the last 76 nucleotides of integrase and first 39 nucleotides of TatD DNase family protein are colored in yellow, green and red (same as color shown in B). (B) Comparison of Tn5307 junction regions in ATCC 11454 and Ge001 with that insert site. Tn5307-specific sequences are underlined and the direct repeated sequence ATCC 11454 and Ge001 is are highlighted in cyan. Sequences identity between the regions flanking Tn5307 in strains ATCC 11454 and Ge001 is indicated (|) 


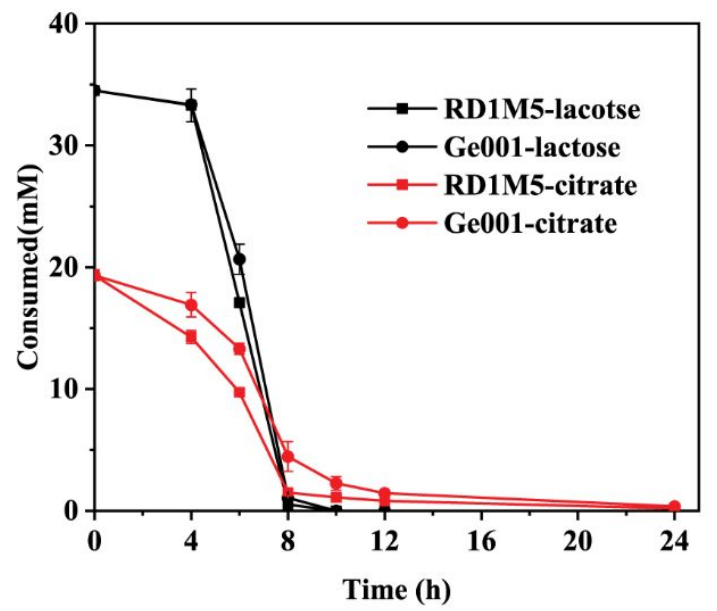

Figure S4. Lactose and citrate consumption of Ge001 in 10\% ML1\%YE. The initial $\mathrm{OD}_{600}$ was 0.05 . All the fermentations were carried out in $25 \mathrm{~mL}$ medium using $300 \mathrm{~mL}$ flasks for two times independently. Error bars indicate standard deviations. 
A

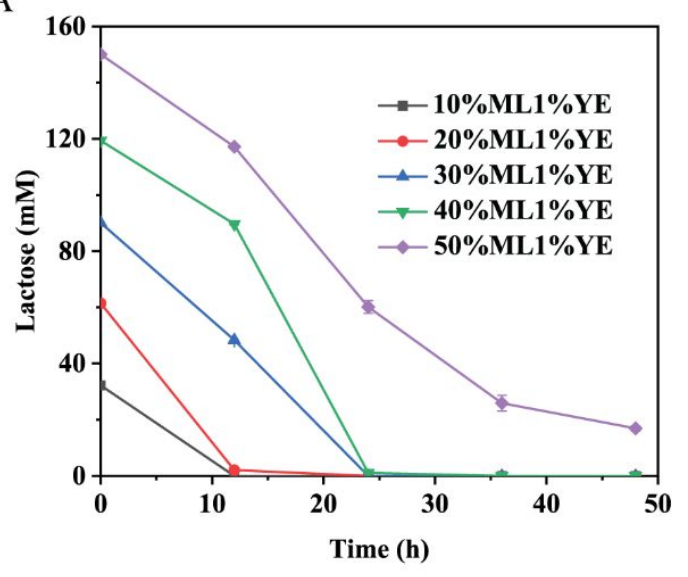

B

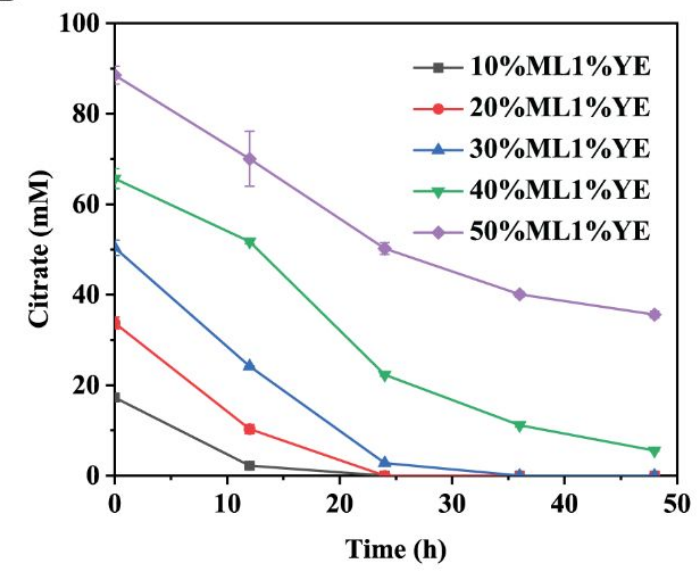

Figure S5. (A) Lactose and (B) citrate consumption of Ge001 in different ML concentration with $1 \%$ YE.The initial OD600 was 0.05 . All the fermentations were carried out in $25 \mathrm{~mL}$ medium using $300 \mathrm{~mL}$ shake flasks for two times independently. Error bars indicate standard deviations. 